\title{
Uma Escrita da Cidade: a Cidade Pré-Modernista e as Transformações Modernizadoras
}

\author{
Mauricio Silva*
}

O presente artigo analisa o processo modernizador por que passa o Rio de Janeiro durante a Primeira República. Aborda, neste sentido, uma gama de conceitos relativos a tais transformações, aliando-as às modificações urbanas concretas sofridas pela Capital Federal no período presidencial de Rodrigues Alves.

Palavras-chave: Rio de Janeiro, urbanismo, modernidade, cidade

The present article analyses the cultural and social context of brazilian history. Adopting a historical perspective, it reveals some urbanistics aspects of brazilian society on Rodrigues Alves government.

Keywords: Rio de Janeiro, urbanization, modernity, city entro do espectro de ações hu$\int$ manas que se podem analisar de modo mais ou menos sistemático, um dos fenômenos mais relevantes é o da urbanização das cidades modernas, o qual teria engendrado - nos dizeres de Henri Lefebvre - uma verdadeira revolução urbana ${ }^{1}$. Com efeito, o processo infrene de industrialização por que passaram as sociedades modernas acabou acarretando um conjunto de transformações sociopolíticas e socioeconômicas que, no limite, re-

\footnotetext{
${ }^{1}$ LEFEBVRE, Henri. La revolución urbana. Madrid: Alianza Editorial, 1983.

* Doutorado e pós-doutorado em Letras Clássicas e Vernaculas pela USP. Professor do program de Pós-Graduação em Educação (Mestrado e Doutorado) da Universidade 9 de Julho. maurisil@gmail.com
} 
sultaram numa extensa remodelação das cidades, com a conseqüiente concentração populacional e dos meios de produção nos grandes centros urbanos, o desenvolvimento da economia capitalista, diversificação das relações sociais, divisão social do trabalho, enfim a modificação de toda a estrutura física e política da cidade que - tendo sido, em épocas remotas, essencialmente mercantil passa a ser, a partir do século XIX, fundamentalmente industrial ${ }^{2}$, para chegar no início do século XXI articulada a um amplo e difuso processo de globalização, cuja base econômica assenta-se num capitalismo financeiro fortemente respaldado pelo imaginário do consumo ${ }^{3}$.

Fenômeno semelhante pôde ser percebido no Brasil a partir do século XIX, época em que o ritmo acelerado da urbanização do país acarretou um crescimento indiscriminado das cidades mais importantes, criando, a seu modo, pólos industriais urbanizados e confirmando a equação de que o crescimento industrial foi, sobretudo no Ocidente, diretamente proporcional ao crescimento urbano ${ }^{4}$.

Evidentemente, semelhantes transformações incidiram de forma mediata sobre a vida das pessoas, alterando alguns hábitos e criando outros, estabelecendo novos padrões de sociabilidade, desestruturando antigos modos de vida e articulando novas formas de convivência, tanto no âmbito privado quando no público. São mudanças que revelam a pertinácia do fenômeno urbano, mas que também tornam clara a premência de se instituir novos instrumentais de leitura e avaliação das relações sociais e culturais citadinas, como que vinculando à realidade diversa que se impõe outros protocolos de legibilidade do espaço urbano.

\footnotetext{
${ }^{2}$ SINGER, Paul. Economia política da urbanização. São Paulo: Brasiliense, 1976; DAVIS, Kongsley. The origin and Growth of Urbanization in the World. The American Journal of Sociology, Vol. 60, No. 05: 429-437, Mar. 1955.

${ }^{3}$ SANTOS, Milton. Por uma outra Globalização. Do Pensamento Único à Consciência Universal. Rio de Janeiro, Record, 2000; CANCLINI, Néstor García. A Globalização Imaginada. São Paulo, Iluminuras, 2003.

${ }^{4}$ LOPES, Juarez Rubens Brandão Lopes. Desenvolvimento e Mudança Social. Formação da Sociedade Urbano-Industrial no Brasil. São Paulo, Companhia Editora Nacional, 1971; SANTOS, Milton. A Urbanização Brasileira. São Paulo, Hucitec, 1994.
} 
De natureza essencialmente plural, a experiência urbana pressupõe, portanto, o estabelecimento de novos parâmetros sociais, mas também psicológi$\cos ^{5}$, constituindo-se, nas palavras de Maria Stella Bresciani,

no observatório privilegiado da diversidade: ponto estratégico para apreender o sentido das transformações, num primeiro passo, e logo em seguida, à semelhança de um laboratório, para definir estratégias de controle e intervenção ${ }^{6}$.

Assim, como fenômeno relativamente novo na história da civilização ocidental, a constituição da cidade urbana cria novos mitos, ideologias e mentalidades e, como contraface desse processo, diferentes possibilidades de leitura, as quais se traduzem como uma inesperada multiplicidade de olhares: olhares especializados e circunstanciais, técnicos e literários, olhares furtivos e circunspectos, desde o olhar do antropólogo e do historiador até o olhar do comerciante, do urbanista ou do simples transeunte. São esses olhares que formam uma espécie de caleidoscópio interpretativo do espaço urbano, em que cada ação especulativa - forjada pela visada atenta de seus habitantes - contribui para a elaboração da idéia que se tem da cidade. Perscrutando seus espaços, sua arquitetura, sua sociabilidade particular, esses olhares constituem leituras construídas pela experiência urbana, ao mesmo tempo em que se consolidam como elementos fundamentais na própria construção do espaço analisado. Cria-se, assim, uma cidade que, por não ser real, mas nascer da experiência do real, revela-se como imagem, uma imagem fugidia, instável, em constante mutação, posto que essencialmente multifacetada. Ilusão de ótica plasmada na vivência urbana de cada cidadão, a imagem da cidade passa assim a se sobrepor à própria cidade enquanto realidade objetiva, desestruturando qualquer pretensa unidade, desconstruindo uma eventual homogeneidade espacial e criando, em lugar de um território reduzido aos limites do espaço político, uma infinidade de cidades, tão variadas, múltiplas e diversas quanto os próprios olhares que as constroem.

\footnotetext{
${ }^{5}$ FISCHER, Claude S. The Urban Experience. New York, Harcourt Brace Jovanovich, 1976.

${ }^{6}$ BRESCIANI, Maria Stella Martins. "Metrópoles: as Faces do Monstro Urbano (As Cidades no Século XIX). Revista Brasileira de História, São Paulo, Vol. 05, No. 08/09: 33-68, Set. 1984/Abr. 1985, p. 39.
} 
Passa a prevalecer, nesse contexto, uma espécie singular de geografia dos sentidos, em que cada parte, real ou imaginária, do espaço urbano, vale não pelo que é em si mesmo, mas pelo que pode vir a ser no âmbito extenso das possibilidade de leitura. Ler a cidade, portanto, torna-se, a um só tempo, um ato político e cultural, na medida em que pressupõe uma intervenção humana capaz de alterar, senão a substância, ao menos a imagem que se tem do objeto analisado.

Com efeito, como afirmou mais de uma vez Lucrécia Ferrara, a percepção urbana é uma prática cultural que se baseia tanto no uso urbano, quanto no hábito, criando, a partir da união desses dois conceitos, uma imagem perceptiva da cidade, a qual necessita ser decodificada. Assim, características culturais sedimentam a cidade como um aglomerado de signos que criam uma linguagem própria do urbano, cujo conhecimento é imprescindível para sua percepção ${ }^{7}$.

Ambivalente e anônimo, o espaço urbano é resultado de alterações constantes, muitas delas decorrentes do processo de industrialização, tornando-se, portanto, objeto de leituras mediadas por linguagens diversas, entre as quais a literária, que procura, ao mesmo tempo, decifrá-la e recriá-la.

Resultado direto e indireto de uma série de renovações ocorridas sobretudo com o advento da chamada Revolução Industrial, as transformações sofridas pelo mundo ocidental durante a passagem do século XIX para o XX acabaram condicionando uma vasta gama de inevitáveis conseqüências, que incidiram inexoravelmente na vida dos indivíduos. Nesse sentido, trata-se de um período que tem como marca distintiva exatamente o afã por uma espécie de volubilidade essencial, que acaba, simbolicamente, se traduzindo numa nova e inesperada sociabilidade.

No âmbito da renovação dos padrões sociais que o mundo ocidental conheceu, a imagem da cidade desempenha um papel fundamental: é ela quem vai sedimentar uma concepção diferente da realidade, sobretudo da realidade urbana. Assim, na passagem do século, ser moderno - isto é, estar em consonância com o

\footnotetext{
${ }^{7}$ FERRARA, Lucrécia d'Aléssio. Ver a Cidade: Cidade, Imagem, Leitura. São Paulo, Nobel, 1988; FERRARA, Lucrécia d'Aléssio. As Máscaras da Cidade. Revista USP, São Paulo, No. 05: 03-10, Mar./Abr./Mai. 1990; FERRARA, Lucrécia d'Allessio. Um Olhar entre Vizinhos. Espaço Social: Linguagem e Interpretação. Espaço e Debates. São Paulo, No. 29: 32-41, 1990; HAUSER, Susanne. The Perception of the City. Espace et Sociétes. Revue Critique Internationale de l'Amenagement de l'Architecture et de l'Urbanization. France, No. 47, 1985.
} 
tempo presente - pressupõe necessariamente estar situado num contexto citadino, fazer parte de um universo urbano ou, na pior das hipóteses, em vias de urbanização. Com efeito, em meio às mais variadas transformações - que vão do âmbito econômico e político ao cultural -, destacam-se as de natureza especificamente urbana, responsáveis não apenas pela reorganização das nações, mas também pelo estabelecimento de um novo modus vivendi, compulsoriamente adaptado às modernas metrópoles emergentes, como se pode verificar em algumas cidades européias, marcadas, no período, pela infrene expansão de seu tecido urbano ${ }^{8}$.

No Brasil, verificou-se um processo análogo, embora com os atrasos comuns aos países subdesenvolvidos e/ou periféricos: como conseqüência inevitável de um processo de industrialização tardio, conhecemos, na virada do século, uma ampla escalada de transformações urbanas, resultando na formação de metrópoles incipientes (São Paulo e Rio de Janeiro) e na consolidação de novos padrões sociais. As grandes cidades - com destaque para o Rio de Janeiro, capital da República recém-proclamada - tornam-se o centro político e administrativo do país, impondo-se econômica e politicamente ao restante da nação e fazendo convergir para si toda sorte de manifestação artístico-cultural. Isso tudo se deve, em grande parte, ao deslocamento populacional que se pôde verificar a partir das últimas décadas do século XIX: com o declínio do patriarcado rural e a afirmação da burocracia estatal urbana, assistimos a uma verdadeira explosão demográfica, que teria conseqüências diretas na imagem da cidade formulada por nossos intelectuais e artistas ${ }^{9}$.

Surgem, nesse sentido, duas perspectivas sob as quais a cidade é contemplada: uma positiva, que procura ressaltar as vantagens das novas formas de sociabilidade urbana, com seus modismos mundanos, seu cosmopolitismo e liberalidades sociais; outra negativa, que busca destacar os malefícios reais e/ou morais próprios de uma cidade que progride compulsória e desordenadamente. Há, assim, toda uma vertente de nossas manifestações culturais assentada no

\footnotetext{
${ }^{8}$ WEBER, Eugen. França Fin-de-Siècle. São Paulo, Companhia das Letras, 1988; SCHORSKE, Carl E. Viena Fin-de-Siécle. Política e Cultura. São Paulo, Unicamp/Companhia das Letras, 1988.

${ }^{9}$ SANTOS, Milton. "Mecanismos de Crescimento Urbano nos Países em Vias de Desenvolvimento". América Latina. Rio de Janeiro, Centro Latino-Americano de Pesquisas em Ciências Sociais, Ano 12, No. 04: 134-148, Out./Dez. 1969; COSTA, Emília Viotti da. Da Monarquia à República: Momentos Decisivos. São Paulo, Brasiliense, 1985; FREYRE, Gilberto. Ordem e Progresso. Lisboa, Livros do Brasil, Vol. I, s.d.
} 
discurso encomiástico voltado ao desenvolvimento urbano, em que se enfatizam principalmente aspectos de nosso progresso material e de uma pretensa evolução social, ambos apresentados sob a roupagem de uma difusa apologia da civilização. Por outro lado, verifica-se igual preocupação em fazer emergir uma crítica acirrada dos efeitos desse desenvolvimento, crítica que se atém ora a seus aspectos materiais (trânsito, barulho, densidade demográfica), ora a seus aspectos morais (prostituição, criminalidade, vícios), sendo que, para efeito de uma caracterização simbólica da cidade, importam mais as críticas de fundo moral, muito mais eficazes na formação de uma determinada semiologia urbana.

Além disso, com o advento da República e com os fatores diversos que levaram à paulatina modernização da sociedade brasileira, a realidade citadina começa a sobrepor-se à campesina. A estrutura social patriarcal, de base rural, cede espaço a uma burocracia urbana, teoricamente civilizada e de modelo europeu: torna-se, com o passar dos anos, impossível a convivência pacífica entre uma oligarquia rural - pretensamente atrasada e ligada a tradições que já não sensibilizam os cidadãos urbanizados - e os grupos sociais que compõem a sociedade urbana, uma burguesia que anseia por reformas pouco estruturais. Em outros termos, assiste-se no Brasil da passagem do século ao triunfo da vida pública (de raízes urbanas) sobre a vida privada (marcada pelo ambiente doméstico da família patriarcal), do bacharel sobre o patriarca ${ }^{10}$. Essa passagem não se deu sem graves consequiências para a sociedade, já que pressupunha uma mudança completa da estrutura familiar brasileira, além de engendrar uma crise política que teria como desfecho, mais de três décadas depois, a Revolução de Vargas. Mais do que isso, trata-se de uma mudança estrutural da economia brasileira, em que um deliberado processo de industrialização passava, pouco a pouco, a substituir o modo agrário de exploração econômica ${ }^{11}$.

A cidade, portanto, impunha-se como centro das atenções do cidadão brasileiro: era o espaço da modernidade e da civilidade, o qual tinha como modelo as grandes metrópoles européias; era o centro político-administrativo do país, isto

\footnotetext{
${ }^{10}$ SALDANHA, Nelson. O Jardim e a Praça. O Privado e o Público na Vida Social e Histórica. São Paulo, Edusp, 1993; MARTINS, Luís. O Patriarca e o Bacharel. São Paulo, Martins, 1953.

${ }^{11}$ SAES, Flávio A. M. de. A Controvérsia sobre a Industrialização da Primeira República. Estudos Avançados. São Paulo,Vol. 03, No. 07: 20-39, Set./Dez. 1989; MENDONÇA, Sonia Regina de. O Ruralismo Brasileiro na Primeira República: Um Debate de Idéias. À Margem. Revista de Ciências Humanas, Rio de Janeiro, Ano I, No. 01: 25-40, Jan. 1993.
} 
é, o locus destinado ao controle burocrático da nação; era, enfim, o objetivo de toda sorte de indivíduos preocupados com o sucesso profissional: descendentes de uma aristocracia rural decadente, intelectuais das províciais, bacharéis recém-formados em busca de uma oportunidade e, last but not least, literatos de todos os cantões do país, os quais se dirigiam para as incipientes metrópoles, a fim de angariar prestígio social, reconhecimento artístico e benefícios públicos diversos. O campo, enquanto isso, ficava relegado à simples condição de referencial de um não muito longínquo passado colonial e monárquico e, por isso mesmo, aos olhos da nova burguesia urbana, um espaço marcado pelo arcaico e pela barbárie. Em suma, enquanto a cidade tornava-se o centro definitivo de poder político, econômico e cultural do país, o campo era visto unicamente como lugar onde se dão as atividades primárias de produção. Não sem razão, os ideólogos da nova realidade urbana veriam no obsoleto universo agrário seu principal antagonista, transformando um debate, a princípio, político-econômico num conflito que contrapunha civilização e barbárie, promovendo, portanto, uma autêntica clivagem ideológica.

Por esses e outros motivos, a chamada Primeira República, no Brasil, tem sido estudada como uma fase histórica pródiga em transformações modernizadoras...

Evidentemente, essas transformações não são homogêneas, nem atingem a todos da mesma maneira. A começar pelos próprios limites espaciais que uma realidade urbana impõe, não se pode afirmar que as transformações ocorridas durante a Primeira República tenham causado os mesmos efeitos na capital da República e nas suas mais distantes províncias; da mesma forma, no que concerne aos limites cronológicos, seria incoerente dizer que tais transformações tenham sido uniformes durante todo o período que se estende da Proclamação da República (1889) à Revolução de Vargas (1930), quando a oligarquia agrária é finalmente afastada do poder, completando-se a primeira fase do nosso período republicano. Ao contrário, é possível verificar, no que diz respeito às transformações do período, sensíveis diferenças entre uma fase de pré-transformações (1889-1902), considerada uma espécie de preparação para alterações mais radicais, encetadas pelo governo de Rodrigues Alves; uma fase de transformações propriamente ditas (1902-1922), quando o país passa por uma série de alterações não apenas estruturais, mas também ideológicas; e uma fase de pós-transformações (1922-1930), em que tais modificações já se revelam amadurecidas e relativamente incorporadas pela sociedade. 
Contudo, é necessário que se desfaçam alguns equívocos conceituais, na medida em as próprias definições de modernidade e modernização, revelam-se, na essência, comprometidas por uma indefectível polissemia.

Procurando fazer uma distinção entre estes dois conceitos, Raymundo Faoro nos ensina que, embora ambos os processos estejam permeados por certo direcionamento ideológico, há diferenças fundamentais entre eles, uma vez que a concretização do primeiro passa pela prática efetiva da cidadania; e a realização do segundo, por uma atuação de natureza visivelmente autoritária, na sua discriminação classista:

diga-se, por enquanto, que a modernidade compromete, no seu processo, toda a sociedade, ampliando o raio de expansão de todas as classes, revitalizando e removendo seus papéis sociais, enquanto que a modernização, pelo seu toque voluntário, se não voluntarista, chega à sociedade por meio de um grupo condutor, que, privilegiando-se, privilegia os setores dominantes ${ }^{12}$.

Ora, não é difícil perceber que a política modernizadora desencadeada a partir de 1889, e até muito antes, no Brasil, esteve mais para um processo de modernização do que de modernidade, sobretudo por sua natureza excludente, como aliás, já ressaltou mais de um estudioso do período ${ }^{13}$. Isso quer dizer que semelhante processo revelou-se, antes, uma atitude de protecionismo classista, uma vez que buscou privilegiar determinados setores da sociedade, efetivando uma modernização de casta. Afastado deste processo, o povo sofreria, mais tarde, todas as conseqüências maléficas do "progressismo" rodriguesalvesiano, que culminaria, entre outras coisas, com a revolta contra a política higienista de Osvaldo Cruz ${ }^{14}$.

${ }^{12}$ FAORO, Raymundo. A Questão Nacional: a Modernização. Estudos Avançados. Universidade de São Paulo, Vol. 06, No. 14: 07-22, Jan./abr. 1992, p. 08.

${ }^{13}$ CARVAlHO, José Murilo de. Os Bestializados: O Rio de Janeiro e a República que não foi. São Paulo, Companhia das Letras, 1989; PINHEIRO, Paulo Sérgio. O Proletariado Industrial na Primeira República. In: FAUSTO, Boris (dir.). História Geral da Civilização Brasileira. O Brasil Republicano. Sociedade e Instituições (1889-1930). Rio de Janeiro, Difel, 1977; FERREIRA, Antonio Celso. No fio da navalha: classes populares na República sob os olhos dos historiadores. História, Universidade Estadual Paulista, São Paulo, Vol. 08: 01-08, 1989; SILVA, Eduardo. As Queixas do Povo. São Paulo, Paz e Terra, 1988; DALLARI, Dalmo de Abreu. A República dos Oligarcas. Revista USP, São Paulo, No. 03: 13-18, Set./Out./Nov. 1989.

${ }^{14}$ MENDONÇA, Marina Gusmão de. Desenvolvimento e Miséria. As Raízes da Revolta de 1904. (Dissertação de mestrado). São Paulo, FFLCH, 1988; SEVCENKO, Nicolau. A Revolta da Vacina. São Paulo, Brasiliense, 1988. 
Desse modo, fatores diversos ligados à modernização do país atuam no sentido de desencadear um processo histórico que consolide, antes, a idéia de uma cidade pré-moderna, estruturalmente diversa tanto da realidade rural quanto da realidade urbana do século XIX. Têm-se, assim, os fundamentos necessários a uma abordagem mais acurada do modelo de cidade que se impõe à população, em que as relações sociais passam a ser pautadas por um outro modelo de comportamento, o qual, num contexto sociológico, pode ser entendido como aspiração a uma sociedade civilizada ${ }^{15}$.

Pode-se ainda dizer que se a constituição de uma nova ordem social e política, no período, não pressupunha necessariamente a criação de um novo código lingüístico a legitimar os aspectos mais pragmáticos dessa mesma ordem (o progresso, a República, as cidades urbanas), é de se acreditar que requisesse, pelo menos, a ativação de um novo discurso, a fim de dar não apenas maior legitimidade às práticas sociais e políticas que então se impunham, mas sobretudo com o propósito de melhor representar uma nova mentalidade que se forjava. $\mathrm{E}$ se a uma mentalidade nova correspondia outro discurso, no caso específico da passagem do século XIX para o XX a linguagem literária passa a servir de locus onde perplexidades relacionadas à nova ordem sociopolítica procuram ser equacionadas. Em nenhum sentido, contudo, pode-se dizer que se trate de um discurso pacificamente incorporado. Ao contrário, reflete as próprias contradições vividas pela sociedade e expressas num imaginário urbano complexo, hesitante, não raro ambíguo. Resultado, talvez, do modo bastante singular com que era traduzido pelos indivíduos a realidade novel: se por um lado, por exemplo, empregava um determinado vocabulário para expressar o reconhecimento de uma dinâmica progressista inaugurada pela segunda Revolução Industrial, esse mesmo vocabulário, por outro lado, serviria para exprimir uma irônica desaprovação desse fenômeno, expressando-se numa singular semântica urbana, na mais pura tradição da história social da linguagem ${ }^{16}$ e revelando um período marcado pela irrupção de índices socioculturais pré-modernos.

\footnotetext{
${ }^{15}$ IANNI, Octávio. Estado e Planejamento Econômico no Brasil. Rio de Janeiro, Civilização Brasileira, 1986; IANNI, Octávio. A Idéia de Brasil Moderno. São Paulo, Brasiliense, 1992; FREYRE, Gilberto. Casa Grande e Senzala. Formação da Família Brasileira sob o Regime da Economia Patriarcal. Rio de Janeiro, José Olympio, 1987.

16 BURKE, Peter. A Arte da Conversação. São Paulo, Unesp, 1995; BURKE, Peter. Variedade de História Cultural. Rio de Janeiro, Civilização Brasileira, 2000.
} 
